\title{
Considering the value of online support groups for colorectal conditions: perspectives from caregivers and adult patients
}

\author{
Laura Judd-Glossy 1,2,3 $\cdot$ Merlin Ariefdjohan ${ }^{1,2} \cdot$ Jill Ketzer $^{3} \cdot$ Kristina Matkins $^{3} \cdot$ Julie Schletker $^{3} \cdot$ Amy Krause $^{3}$. \\ Hope Simmons ${ }^{3} \cdot$ Alberto Pena $^{3} \cdot$ Luis De La Torre ${ }^{3} \cdot$ Andrea Bischoff $^{3}$
}

Accepted: 1 September 2021 / Published online: 25 September 2021

○ The Author(s), under exclusive licence to Springer-Verlag GmbH Germany, part of Springer Nature 2021

\begin{abstract}
Purpose To evaluate the benefits of participating in an online support group for caregivers of children with a colorectal condition or adult patients with a similar condition.

Methods An electronic survey was administered to members of an international online support group (18 items for caregivers; 15 for patients). Items included demographics, medical diagnosis, potential benefits, and overall experiences in the group. Quantitative results were summarized as descriptive trends, while qualitative responses were summarized thematically.

Results Respondents (102 caregivers, 6 patients) were primarily female, 35-44 years old, Caucasian, and resided in the United States. Most respondents learned about the support group from medical providers or online search. Cited benefits included learning information, gaining support, forming connections through shared experience, and utilizing a unique resource. Being a member of the group was helpful to respondents, improved their mental health and access to health information, and they would recommend the group to others.

Conclusion Participation in online support groups offers educational and emotional benefits to patients/caregivers which complements the medical support from their colorectal teams. Thus, colorectal providers need to be aware of the availability and potential benefits of these groups, and encourage their patients/caregivers to be actively involved.
\end{abstract}

Keywords Support group $\cdot$ Anorectal malformations (ARM) $\cdot$ Psychosocial functioning $\cdot$ Hirschsprung disease $\cdot$ Fecal incontinence $\cdot$ Parents'/Caregivers'/Patients' perspectives

\section{Abbreviations \\ ARM Anorectal malformations \\ HD Hirschsprung disease \\ IA Imperforate anus}

\section{Introduction}

Participation in support groups has been shown to be helpful for patients with acute and chronic illnesses [1]. With increased availability of the internet and other advances in virtual communication technology, many support groups have transitioned from in-person format to online. Conducting such support groups in digital platforms have allowed for increased participation and flexibility [2]. Notably, patients with relatively rare medical conditions have indicated that it could be challenging for them to connect with others who have similar medical concerns within their direct community. However, the availability of online support groups has created another outlet for them to form connections and thus circumvent this obstacle [3]. Other benefits for participation in these groups that have been cited by individuals with medical conditions include the opportunity to share and gain information, provide support to others, and seek validation from others in similar situations [4].

2 Pediatric Mental Health Institute, Children's Hospital Colorado, Aurora, CO, USA

3 International Center for Colorectal and Urogenital Care, Children's Hospital Colorado, Aurora, CO, USA 
Colorectal conditions, including anorectal malformations (ARM), Hirschsprung disease (HD), and spinal conditions that affect the bowel, are relatively rare [5-7]. Nonetheless, these conditions pose significant challenges in daily living that require lifestyle, dietary, and social modifications [8]. Given the high frequency of fecal incontinence and the need for rectal enemas or laxatives to manage their colorectal conditions, individuals may feel stigmatized to speak openly about their illness [9], which may further hamper forming social relationships with others. Through its indirect nature of digital communication, participation in online support groups could provide an alternative way to foster connections among these individuals and their caregivers. Research has confirmed the existence of several social-media based support groups for colorectal conditions [10, 11]. However, studies that have directly examined the function and benefits of participating in these online colorectal support groups from the members' perspectives are limited.

The aim of the present study is to gather the sentiments of caregivers of a child with a colorectal condition and those of adult patients with a similar condition, who are members of an online support group, to determine potential benefits of participation. Their thoughts on ways to improve the support structure were also surveyed. Collectively, their perspectives and suggestions may inform ways that medical professionals and laypeople (including caregivers) could further support individuals with a colorectal condition in more thoughtful and meaningful ways.

\section{Methods}

\section{Structure of the support group}

The Colorectal Support Network was created in 2018 in collaboration between caregivers of patients with colorectal conditions and providers at Children's Hospital Colorado. The primary purpose of this collaboration was to support caregivers of children with colorectal conditions using social media. The group operates through a private Facebook site and maintains all communication with the members through this online platform. While members can maintain as much of an online presence as they wish within the site, members of the leadership team take a proactive role in governing the support group. For example, they meet quarterly to evaluate the functioning of the group, discuss strategies to increase the number of participants, and brainstorm monthly topics to promote interaction and engagement between members. Current leadership team members include parents of children with colorectal conditions, adult patients, and several providers from Children's Hospital Colorado. All members of this group were vetted for inclusion by the account administrator since it is not an open group setting. Potential members are required to be 18 years old and above, could reside anywhere in the world, and have been diagnosed with a colorectal condition or are the parent/caregiver of a child with a colorectal condition. To date, there are approximately 750 active members globally.

\section{Survey and study participants}

A brief survey was developed by the study authors to evaluate members' experience of participating in an online support group for colorectal conditions. The survey was separated into two tracks, whereby one was for parents/caregivers of a child with a colorectal condition (18 items), and the other for patients with a colorectal condition (15 items). Basic demographic and clinical profiles, sentiments related to the perceived value, benefits and experience of participating in an online support group, and open-ended comments were gathered from both tracks.

The online survey was administered using the SurveyMonkey ${ }^{\mathrm{TM}}$ platform. The authors contacted the account administrator who oversees the site prior to the study to obtain permission to recruit participants from the group. Once permission was granted, a survey link was circulated to the members by the account administrator. Additionally, the account administrator sent out reminders soliciting participation although it was made clear that participation was completely voluntary. Personal identifiers including IP addresses were not collected during the survey to preserve anonymity of respondents. The survey was live for approximately 3 weeks from May 2, 2021 to May 23, 2021.

This study received the approval of the Colorado Multiple Institutional Review Board (COMIRB), which provides regulatory oversight for human subject research at the study site (Protocol 21-3162).

\section{Data analyses}

Quantitative data were analyzed using descriptive statistics (e.g., count, percent frequency) and summarized as pertinent trends when applicable (SAS Studio, SAS Inc., Cary, NJ). A thematic analysis framework was used to organize and identify major themes from open-ended responses for respective survey questions. These qualitative responses were first independently reviewed by authors (LJG, MA) to minimize subjectivity, and then discussed and grouped together by these authors as major themes supported by pertinent quotes through a process of inductive reasoning. This qualitative research methodology is largely based on the Consensual Qualitative Research (CQR) process [12]. Data from parent/ caregiver respondents were analyzed separately from those of adult patient respondents. 


\section{Results}

A total of 112 respondents (106 parents/caregivers and 6 adult patients) participated in the survey contributing to a response rate of approximately $15 \%$. However, data from four parent/caregiver respondents had to be excluded from analyses because they did not complete a large portion of the survey. Thus, analyses were based on data from 102 parents/ caregivers and 6 adult patients.

\section{Demographic and clinical profile of respondents}

Basic demographic information and clinical profile of the respondents is summarized in Table 1. Briefly, most parent/caregiver respondents were female (93.1\%), Caucasian (70.6\%), between the ages of 35 to 44 years old (51.0\%), married $(90.2 \%)$, and completed college (52.9\%). They primarily identified as the parent/caregiver of only one child with a colorectal condition (98.1\%); the majority of these children were male $(59.6 \%)$, between the ages of $0-4$ years old (34.6\%), and diagnosed with ARM (84.6\%). Among the patient respondents, they were mostly female (66.7\%), between the ages of 35-44 years old (33.3\%), single (33.3\%), and completed college (66.7\%). All patient respondents identified as Caucasian and diagnosed with ARM (100\%). Additionally, the majority of parents/caregivers and patient respondents resided in the United States $(73.5 \%$ and $83.3 \%$, respectively).

\section{Respondents' experience in participating in the online support group}

Table 2 outlines survey results reflecting respondents' experience in participating in the online support group. Briefly, the majority of parents/caregivers and patient respondents had been a member of the online support group for more than a year (68.6\% and $83.3 \%$, respectively). Parent/caregiver respondents indicated first learning about the support group from a clinical provider or medical center (32.4\%), their own search online (e.g., in Facebook, Google, or other websites; $32.4 \%$ ), and through recommendation from others (16.5\% word-of-mouth, $7.8 \%$ friends, and $1.0 \%$ family member). Patient respondents indicated a slightly different trend whereby they were introduced to the support group through online search (33.3\%), recommendation from others (33.3\% word-of-mouth, $16.7 \%$ family member, but not from friend), and through their clinical provider or medical center $(16.7 \%)$. In terms of frequency of visiting the support group site, parent/caregiver respondents indicated at least once per week $(51.0 \%)$ followed by at least once per month $(27.5 \%)$, which is similarly indicated by patient respondents $(83.3 \%$ and $16.7 \%$, respectively). Notably, $81.4 \%$ of parent/caregiver respondents and $83.3 \%$ of patient respondents indicated that the online support group had met their needs. Approximately $15.5 \%$ of parent/caregiver respondents and $16.7 \%$ of patient respondents reported they were unsure about this. An additional $3.1 \%$ of parent/caregiver respondents indicated that the site did not sufficiently meet their needs, whereas none of the patient respondents mentioned this sentiment.

\section{Perceived benefits of participating in the online support group}

Both parent/caregiver respondents and patient respondents identified multiple benefits from being a member of this support group. These included gaining emotional support from other members (indicated by $76.5 \%$ parent/caregiver respondents and $66.7 \%$ patient respondents), learning new information from the site and other members $(98.0 \%$; $83.3 \%)$, making new friends $(20.6 \% ; 50.0 \%)$, and having the opportunity to provide information or support to other members $(65.7 \%$; $100.0 \%)$ (Table 2$)$.

Notably, most parent/caregiver respondents indicated positive sentiments (i.e., as denoted by a stronger combination rating towards agree to strongly agree than a combination of disagree and strongly disagree) related to their participation in the support group. They reported improvement in their mental health and access to health information, as well as helpfulness of the platform for parents/caregivers caring for a child with a colorectal condition (Fig. 1). However, they also indicated more neutral sentiment towards their involvement in the online support group having any benefits for their children, specifically in terms of improving children's mental health, physical health, quality of life, and adherence to medical regimen (Fig. 1). Several parent/ caregiver respondents mentioned that the content and discussion within the support group was not relevant to them or their child, which was typically attributed to the child having a specific condition or of a certain developmental level that was not commonly discussed by other members. Others also noted that information and discussion content posted by other members could be distressing and overwhelming. These factors led some parents/caregivers to limit their frequency of visit to, and participation in the discussion thread within the platform. Nonetheless, the majority of parents/ caregivers indicated a strong agreement (at least 90\%) for wanting to recommend the support group to other parents of children with a colorectal condition and other patients with similar condition (Fig. 1).

Overall, patient respondents also indicated positive sentiments towards being a member of the support group, particularly in terms of improving their access to health information, mental health, and quality of life. A majority of these respondents (83.0\%) also rated agree to strongly 
Table 1 Basic demographic and clinical profile of respondents (as count and \% frequency)

\begin{tabular}{|c|c|c|}
\hline Characteristics & $\begin{array}{l}\text { Parents/caregivers } \\
(N=102)\end{array}$ & $\begin{array}{l}\text { Patients } \\
(N=6)\end{array}$ \\
\hline \multicolumn{3}{|l|}{ Country of residence } \\
\hline US & $75(73.5)$ & $5(83.3)$ \\
\hline Non-US & $27(26.5)$ & $0(0)$ \\
\hline Prefer not to disclose & $0(0)$ & $1(16.7)$ \\
\hline \multicolumn{3}{|l|}{ Age group } \\
\hline 18-24 years old & $0(0)$ & $1(16.7)$ \\
\hline $25-34$ years old & $18(17.6)$ & $1(16.7)$ \\
\hline 35-44 years old & $52(51.0)$ & $2(33.3)$ \\
\hline $45-54$ years old & $26(25.5)$ & $1(16.7)$ \\
\hline 55-64 years old & $5(4.9)$ & $1(16.7)$ \\
\hline $65-74$ years old & $1(1.0)$ & $0(0)$ \\
\hline 75 years old or older & $0(0)$ & $0(0)$ \\
\hline \multicolumn{3}{|l|}{ Gender } \\
\hline Female & $95(93.1)$ & $4(66.7)$ \\
\hline Male & $6(5.9)$ & $2(33.3)$ \\
\hline Transgender & $0(0)$ & $0(0)$ \\
\hline Prefer not to disclose & $1(1.0)$ & $0(0)$ \\
\hline \multicolumn{3}{|l|}{ Race/ethnicity } \\
\hline American Indian or Alaska Native & $0(0)$ & $0(0)$ \\
\hline Asian & $3(2.9)$ & $0(0)$ \\
\hline Black or African American & $0(0)$ & $0(0)$ \\
\hline Hispanic or Latino & $13(12.7)$ & $0(0)$ \\
\hline Native Hawaiian or other Pacific Islander & $0(0)$ & $0(0)$ \\
\hline Middle Eastern or North African & $2(2.0)$ & $0(0)$ \\
\hline White or Caucasian & $72(70.6)$ & $6(100.0)$ \\
\hline Multi-racial & $8(7.8)$ & $0(0)$ \\
\hline Prefer not to disclose & $4(3.9)$ & $0(0)$ \\
\hline \multicolumn{3}{|l|}{ The highest level of education completed } \\
\hline Elementary/middle school & $0(0)$ & $0(0)$ \\
\hline High school & $15(14.7)$ & $1(16.7)$ \\
\hline College & $54(52.9)$ & $4(66.7)$ \\
\hline \multirow[t]{2}{*}{ Advanced degree } & $33(32.4)$ & $1(16.7)$ \\
\hline & $0(0)$ & \\
\hline \multicolumn{3}{|l|}{ Current relationship } \\
\hline Married & $92(90.2)$ & $3(50.0)$ \\
\hline Separated or divorced & $4(3.9)$ & $1(16.7)$ \\
\hline Single & $3(2.9)$ & $2(33.3)$ \\
\hline Other & $3(2.9)$ & $0(0)$ \\
\hline \multicolumn{3}{|l|}{ Age of the child ${ }^{\mathrm{a}, \mathrm{c}}$} \\
\hline $0-4$ years old & $36(34.6)$ & Not applicable \\
\hline $5-8$ years old & $32(30.8)$ & \\
\hline 9-12 years old & $13(12.5)$ & \\
\hline 13-17 years old & $12(11.5)$ & \\
\hline 18 years or older & $10(9.6)$ & \\
\hline Prefer not to disclose & $1(1.0)$ & \\
\hline \multicolumn{3}{|l|}{ Gender of the child ${ }^{\mathrm{a}, \mathrm{c}}$} \\
\hline Female & $40(38.5)$ & Not applicable \\
\hline Male & $62(59.6)$ & \\
\hline Transgender & $0(0)$ & \\
\hline Prefer not to disclose & $2(1.9)$ & \\
\hline
\end{tabular}


Table 1 (continued)

\begin{tabular}{lcc}
\hline Characteristics & $\begin{array}{l}\text { Parents/caregivers } \\
(N=102)\end{array}$ & $\begin{array}{l}\text { Patients } \\
(N=6)\end{array}$ \\
\hline Colorectal condition diagnosis ${ }^{\mathrm{b}, \mathrm{c}}$ & & \\
Anorectal malformation (ARM) & $88(84.6)$ & $6(100.0)$ \\
Hirschsprung disease (HD) & $7(6.7)$ & $0(0)$ \\
Idiopathic constipation & $1(1.0)$ & $0(0)$ \\
Spinal condition & $3(2.9)$ & $0(0)$ \\
Prefer not to disclose & $2(1.9)$ & $0(0)$ \\
Other & $3(2.9)$ & $0(0)$ \\
\hline
\end{tabular}

${ }^{\text {a }}$ Pertinent to parent/caregiver respondents only

${ }^{\mathrm{b}}$ Parent/caregiver respondents indicated diagnosis for their child, while patient respondents indicated diagnosis for self

${ }^{\mathrm{c}}$ There were two parent/caregiver respondents who indicated they each were caring for another child with a colorectal condition. Thus, there was a total of 104 children for these variables

Table 2 Respondents' experience being in the support group (as count and \% frequency)

\begin{tabular}{|c|c|c|}
\hline Characteristics & $\begin{array}{l}\text { Parents/caregivers } \\
(N=102)\end{array}$ & $\begin{array}{l}\text { Patients } \\
(N=6)\end{array}$ \\
\hline \multicolumn{3}{|c|}{ How long have you been a member of the support group? } \\
\hline Less than 6 months & $15(14.7)$ & $0(0)$ \\
\hline $6-12$ months & $17(16.7)$ & $1(16.7)$ \\
\hline More than a year & $70(68.6)$ & $5(83.3)$ \\
\hline \multicolumn{3}{|l|}{ How did you first learn about the support group? } \\
\hline Clinical provider/medical center & $33(32.4)$ & $1(16.7)$ \\
\hline Family member & $1(1.0)$ & $1(16.7)$ \\
\hline Friend & $8(7.8)$ & $0(0)$ \\
\hline Word-of-mouth & $27(26.5)$ & $2(33.3)$ \\
\hline Online (e.g., Facebook, Google, Websites) & $33(32.4)$ & $2(33.3)$ \\
\hline \multicolumn{3}{|c|}{ How often do you visit the support group Facebook page? } \\
\hline At least once per day & $11(10.8)$ & $0(0)$ \\
\hline At least once per week & $52(51.0)$ & $5(83.3)$ \\
\hline At least once per month & $28(27.5)$ & $1(16.7)$ \\
\hline Less than once a month & $11(10.8)$ & $0(0)$ \\
\hline \multicolumn{3}{|l|}{ Does this meet your needs? ${ }^{\mathrm{a}}$} \\
\hline Yes & $79(81.4)$ & $5(83.3)$ \\
\hline No & $3(3.1)$ & $0(0)$ \\
\hline Unsure & $15(15.5)$ & $1(16.7)$ \\
\hline \multicolumn{3}{|c|}{ What benefit(s) do you receive from being a member of the support group? } \\
\hline Gain emotional support & $78(76.5)$ & $4(66.7)$ \\
\hline Learn new information & $100(98.0)$ & $5(83.3)$ \\
\hline Make friends & $21(20.6)$ & $3(50.0)$ \\
\hline Provide information or support to others & $67(65.7)$ & $6(100.0)$ \\
\hline
\end{tabular}

${ }^{a}$ Five parent/caregiver respondents did not provide any answer contributing to $N=97$ for this variable agree that being a member of the support group was helpful for them as a patient with a colorectal condition. Although they did not express any negative sentiments (i.e., disagree to strongly disagree), approximately $80.5 \%$ of patient respondents had neutral sentiments towards whether their participation in the support group had 
I would recommend the support group to patients with colorectal conditions

I would recommend the support group to parents of children with colorectal conditions

Being a member of the support group has improved my mental health

Being a member of the support group has improved my access to health information

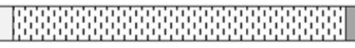
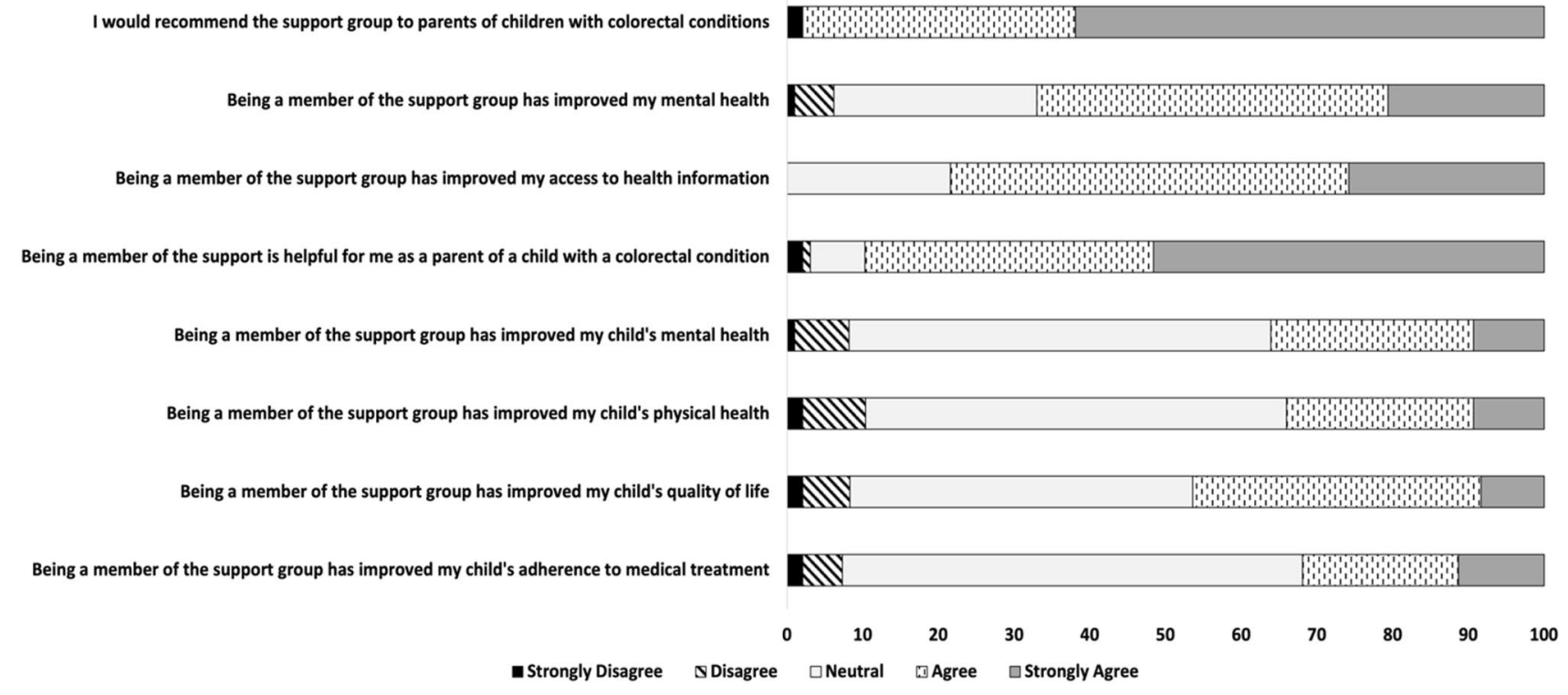

Fig. 1 Parents'/Caregivers' sentiments about being a member of the online support group, as ranked based on a 5-point Likert scale (i.e., strongly disagree, disagree, neutral, agree, strongly agree; as \% frequency; $N=97$ since 5 respondents did not provide any ratings)

I would recommend the support group to patients with colorectal conditions

I would recommend the support group to parents of children with colorectal conditions

Being a member of the support group has improved my access to health information

Being a member of the support group has improved my mental health
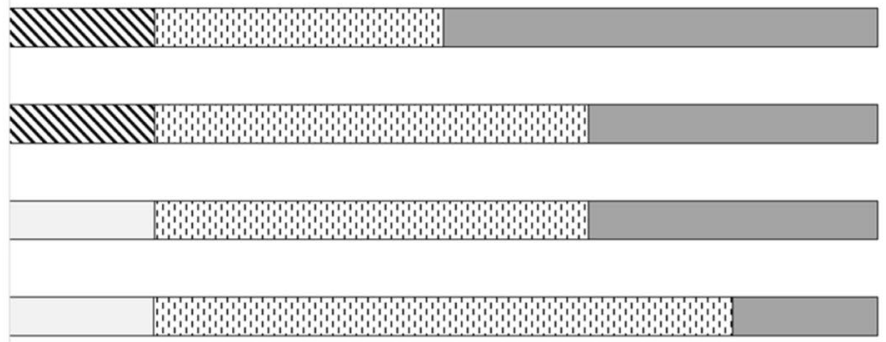

Being a member of the support group has improved my physical health

Being a member of the support group has improved my quality of life

Being a member of the support group has improved my adherence to medical treatment

Being a member of the support group is helpful for me as patient with a colorectal condition

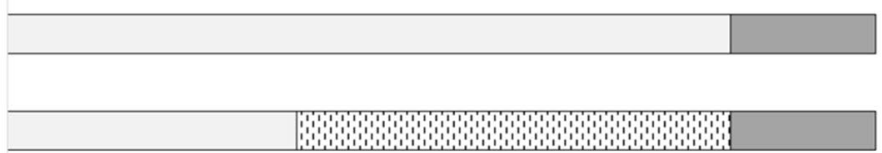

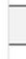
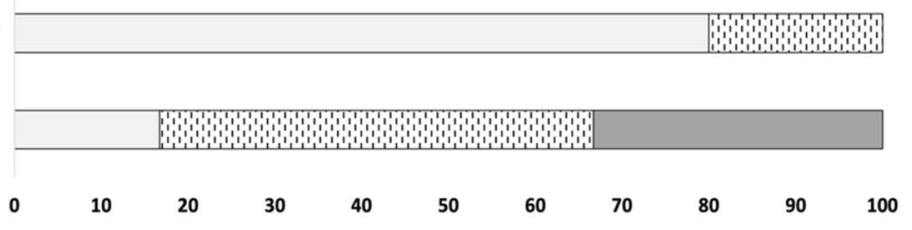

घStrongly Disagree $\$$ Disagree $\square$ Neutral $\square$ Agree $\square$ Strongly Agree

Fig. 2 Patients' sentiments about being a member of the online support group, as ranked based on a 5-point Likert scale (i.e., strongly disagree, disagree, neutral, agree, strongly agree; as \% frequency; $N=6$ )

improved their physical health and adherence to medical treatment. Similarly to parent/caregiver respondents, they showed strong agreement (approximately at least 80\%) towards recommending the support group to patients with a colorectal condition and other parents/caregivers whose 
children have similar condition. These results are summarized as Fig. 2.

\section{Perspectives of parent/caregiver and patient respondents about the value of participating in the online support group}

Four major themes emerged when respondents were asked about factors that made them join the online support group. These include: (i) getting support from non-clinician community; (ii) forming connections with others through shared experiences; (iii) educating self and others by sharing information; and iv) through medical referral. There were only four comments from patient respondents, but they largely matched these themes. When asked about what they like about participating in this online support group, respondents cited positive sentiments that overlap with the first three themes cited above and that this platform offered a unique resource. There were six comments from patient respondents for this prompt. Similar to the earlier question, the themes that emerged matched those from parent/caregiver respondents. Further, several parent/caregiver respondents shared negative sentiments related to the choice of social media platform the support group was being maintained in, irrelevant content to their child's condition, and the lack of inperson connection. However, the overall sentiments of both parent/caregiver and patient respondents were overwhelmingly positive. Parent/caregiver respondents also suggested that the support group could be more interactive (based on their experience with other online support groups), add information about various colorectal conditions instead of focusing only on the most common diagnoses, facilitate discussion in small break-out groups, and encourage the sharing of positive news to celebrate together with other members instead of posting only medical challenges. None of the patient respondents offered negative sentiments or suggestions to improve the support group structure. Pertinent quotes supporting these themes are listed in Table 3.

\section{Discussion}

Online support groups provide easily accessible support and are particularly helpful for patients coping with chronic medical illnesses. Patients with colorectal conditions and their families may be in particularly high need for this type of support given the possible stigma associated with disclosing medical information about the patient's condition and treatment directly to their peers. This study reviewed the function and perceived benefits of participating in an online support group from the perspectives of parents/caregivers of patients with colorectal conditions, as well as from adult patients.
In our study, both parent/caregiver and patient respondents noted that participating in the online support group provided them with significant support, helpful information, and an opportunity to connect with others over a shared experience. These findings were consistent with previous examinations of the role of online support groups in the lives of patients with chronic medical conditions [4]. Overall, key findings from these studies and ours speak to the importance of online support groups in providing a convenient platform to foster social connections that may facilitate bonding and establishing a sense of 'community'. Social support is particularly important among patients with chronic medical conditions including colorectal conditions (and their parents/caregivers), as it can help "normalize the diagnosis and ....alleviate the sense of extreme isolation associated with these complex problems" [13] (p. 6). Grano and colleagues [14] found that the level and quality of social support that mothers of children with ARM received could be a mediating factor in their ability to support the child's medical condition (e.g., fecal incontinence) and the child's quality of life. In other words, parents/caregivers can most likely help their child to better cope with incontinence when they feel socially and emotionally supported themselves.

The success of this particular online support group is likely related to the structure and format of the group whereby the leaders intentionally facilitate monthly conversations about relevant topics (e.g., tips and tricks for success at school, how to negotiate with insurance companies about medical supplies, and strategies to fit daily enemas into your child's daily schedule). It has also been helpful to have an advisory board that includes medical professionals such as physicians, psychologists, and social workers. Such a combination of parent/adult patient-run groups that partner with medical providers presents an ideal support group scenario. It allows medical experts to provide informal consultation and evidence-based guidance to the group via the group's leaders, who have direct connection and communication with these experts. The leaders can also help families to learn how and when to reach out to various medical providers to address concerns as they arise.

While participation in online support groups can provide significant emotional support and information, they certainly cannot replace the importance of a trusted relationship with a medical provider who has expertise in colorectal conditions. Jacobs and colleagues [10] found in their study of online support groups for caregivers of children with various congenital conditions (including ARM) that there was a need for greater support and partnership between caregivers and their healthcare provider. In this study, they noted that patients and families wanted to have more opportunities to interact with their providers within an online setting. This is consistent with our finding whereby one respondent mentioned "I think it is good to find support and feel that I am 
Table 3 Major themes related to reasons or other comments for joining the online support group and pertinent quotes contributed by parent/caregiver respondents

Question prompt: what led you to join the online support group? $(N$ of parent/caregiver respondents $=71 ; N$ of patient respondents $=4)$

Major themes

Getting support from non-clinician community

Forming connections with others through shared experiences

Educating self and others by sharing information

Through medical referral

\section{Pertinent quotes}

From parent/caregiver respondents

"Support after my daughter was diagnosed with ARM"

"Wanted to connect with other parents of children with similar conditions, mostly to ask for opinions/strategies/products from day-to-day caregivers"

"We were beginning enemas and looking for support from other parents who had similar experiences"

"To receive support, and to offer support as able, along this journey of caring for a child with a colorectal condition"

From patient respondents

"Be in a supportive and informative community..."

From parent/caregiver respondents:

"It [the support group] sounded like a great place to talk with parents who 'get it'."

"Support from parents who had already been in my shoes"

"Knowing there was a group of people that could relate to the situation like mine"

"Finally finding a group of other parents who have journeyed and continue to journey the same path I am on with my son"

From patient respondents

"I was born with IA, and I wanted to connect with others who were born with this rare condition"

"Community, support, information"

From parent/caregiver respondents:

"I enjoy seeing suggestions from others that are familiar with my child's condition"

"To learn from other parents so I can provide best care to my daughter"

"Wanting more information from the top hospital out there and wanting to hear about other families' experiences. Initially I needed to know and see that other families could survive and even thrive when their children had such complex medical needs."

"To help other parents of newly diagnosed kids"

From parent/caregiver respondents

"We were recommended by our doctor to look into joining"

"...it was recommended by the social worker at the hospital that I join the colorectal support network as it might help me with my daughter"

From patient respondents

"I'm a Peña patient" 
Table 3 (continued)

Question prompt: what do you like/dislike about being in the group? Are there any other comments about being a member of an online support group that you would like to share?

$(N$ of parent/caregiver respondents $=97 ; N$ of patient respondents $=6)$

Major themes

Positive sentiments: getting support from non-clinician community

Positive sentiments: forming connections with others through shared experiences

Positive sentiments: educating self and others by sharing information

\section{Pertinent quotes}

From parent/caregiver respondents

"I agree that this group is a good thing as it has supported me emotionally dealing with my daughter's condition..."

"It is hard to connect with people in-person due to the rarity of the condition, so the online connection is great"

"Being part of a platform gives me encouragement and mental support to know I'm not alone"

"The group is encouraging, informative, and very positive in their communications back and forth"

From patient respondents

"I like knowing there is a place I can post questions or concerns that others instantly "get" without having to go through all of the explanations"

From parent/caregiver respondents

"I find it very helpful. I can talk to others who can relate and I don't feel so insecure about talking about my child's condition...I actually feel comfortable talking about things there as to where I don't so much in other groups."

"It also helped me knowing I'm not alone in this healthcare journey when it gets stressful"

"Yes, because only parents who go through this have the same feelings of fear, doubt, pride, joy ... we are walking the same path, some further ahead than others and we need to support each other, no matter how many kilometers away we are."

"Having a platform where I can show my son other kids with similar conditions, doing enemas and living the same lifestyle helps him be more comfortable with his daily life"

From patient respondents

"Feel like a part of a wonderful community of people who understand what it's like to live with ARM"

From parent/caregiver respondents

"I have gotten a lot of helpful information and learned so many things I didn't know."

"Love being able to share with others and learn methods that have worked in real life"

"It offers not only support, but informational materials on topics I'm interested in. I've learned many tips on certain ways to care for my son, which I hadn't seen before."

From patient respondents

“...As a patient, [the support group] provides me with emotional support but is most useful in giving me creative ideas to manage everyday life with a colorectal malformation." 
Table 3 (continued)

Question prompt: what do you like/dislike about being in the group? Are there any other comments about being a member of an online support group that you would like to share?

$(N$ of parent/caregiver respondents $=97 ; N$ of patient respondents $=6)$

\section{Major themes}

Positive sentiments: unique resource

Negative sentiments

Other comments: suggestions to consider

\section{Pertinent quotes}

From parent/caregiver respondents

"Where we live, information and support for IA/ARM specifically is severely lacking. If it weren't for the connections we've made through [the support group] and similar groups, our son wouldn't have the quality of life he has now."

"I am a parent of a teenager and I wish this group was around when I was in the thick of it and my child was much younger"

"Being from Australia, it's great to connect with parents experiencing the same issues we do, just in another country, and having access to hear about different medical approaches"

From patient respondents

"As someone born in the early 80's, medical information (on colorectal malformation) was extremely limited for my parents when it came to caring for me as a child... Now as an adult where I'm starting to have some complications, I wanted to connect with other adults born with this condition and to learn different ways on how (to) deal with certain issues."

From parent/caregiver respondents

"I would prefer it didn't require being on Facebook"

"We're new to HD after a late diagnosis and a lot of our experience differs"

"I love the online support, would LOVE to have an in person support group near me...but just not sure that is feasible. I love being able to get advice from other parents who have been there but the connection never extends beyond that."

"Initially it was helpful, but it has become a source of stress. I don't bother asking questions because I know the answers to expect."

"The members in other (support) groups tend to share more and participate more. So this one has far less information and support."

From patient respondents

None indicated any negative sentiments

From parent/caregiver respondents

"I do feel like some of the parent run groups on FB provide more information which would be nice for (the support group) to do"

"I would like to learn some more development about ARM"

"I like the idea of pairing into smaller groups based on where you live or what your child has been diagnosed with... I want to talk to other mom's who can understand"

"I don't often see posts by parents of other children with the same condition as my son, or their kiddos are at a very different stage of condition management so their posts are mostly unrelated to my dayto-day life. I know very little about any of the other group members, their kiddos, or their medical journey. People mostly post when something is wrong (or they're worried it might be), but it would be nice if people would share more positive stories/small wins so that we could celebrate as a group."

From patient respondents

None indicated any suggestions to consider 
not alone, but I wouldn't say that it meets all of my needs-I think that being in contact with his care team at Children's Hospital is the most important for need fulfilment." Overall, sentiments such as this one demonstrates the importance of providing multiple types of support and resources for the patient and their family, whether they are delivered by the healthcare team or other sources such as an online support group.

Finally, we would be remiss to not acknowledge a unique benefit of the role of online support groups within the context of the COVID-19 pandemic. Namely, this virtual communication format provides the opportunity for individuals to remain actively connected to others in a physically safe manner. While many support groups had already been present online and fostered connections among individuals globally even in previous years, the recent pandemic may have further solidified the future of telehealth as an alternative means to foster connection, establish a sense of community, and offer support despite times of social distancing.

This study had several limitations. First, survey respondents were not a heterogeneous group, particularly given that all participants spoke English and most lived in the United States. Thus, these results may not be representative of the experiences of other groups, particularly non-English speakers or those who live outside of the United States. Additional studies are needed to evaluate the experiences of minority groups (e.g., non-English speakers, communities of color) and individuals residing in other countries than the United States. In addition, the survey was administered to members of only one online support group, while many more support groups for individuals caring for/with a colorectal condition exist within various social media platforms.

Nonetheless, this study provided some insights on the important role and benefits of participating in an online support group for individuals caring for/with a colorectal condition. This can be summed up through the sentiment of a patient respondent in our study who mentioned that the online support group "provides a network of connections, access to information, emotional support, and others' experiences/successes/failures in treatment and management of condition." Clearly, the support given by various medical teams remains valuable to these individuals. However, having the connection and support of others in similar conditions can be equally helpful and transformative as they navigate the challenges of their situation. Thus, whenever possible, both types of support should be made available and accessible to parents/caregivers and individuals with colorectal conditions alike.

\section{Conclusion/clinical implication}

Caregivers and adult patients who participate in online support groups can receive significant emotional and educational benefits, which complement the medical support they obtain from their colorectal teams. It is important for colorectal providers to be aware of the availability of these groups and the potential benefits of participation, as well as encourage their patients and parents/caregivers to be actively involved in these alternative support systems. Colorectal teams are well positioned to connect patients and families with these unique and helpful resources, which can improve the overall physical and psychological well-being of patients and their families.

Acknowledgements The authors of this study would like to thank the leaders and members of the Colorectal Support Network for participating in the survey.

Funding None.

\section{Declarations}

Conflict of interest All authors declare that they have no conflict of interest.

Human and animal rights This retrospective study was approved by the Colorado Multiple Institutional Review Board (COMIRB; Protocol 21-3162). All co-investigators underwent appropriate compliance and ethics training prior to the study onset. Personal identifiers of survey respondents including IP addresses were not collected (i.e., anonymous survey) to preserve confidentiality of participants. All data were stored on a password protected server and data access was limited to only coinvestigators to ensure data security.

\section{References}

1. Davison KP, Pennebaker JW, Dickerson SS (2000) Who talks? The social psychology of illness support groups. Am Psychol 55(2):205-217

2. Chung JE (2014) Social networking in online support groups for health: how online social networking benefits patients. J Health Commun 19(6):639-659. https://doi.org/10.1080/10810730.2012. 757396

3. Delisle VC, Gumuchian ST, Rice DB, Levis AW, Kloda LA, Körner A, Thombs BD (2017) Perceived benefits and factors that influence the ability to establish and maintain patient support groups in rare diseases: a scoping review. Patient 10(3):283-293. https://doi.org/10.1007/s40271-016-0213-9

4. Haik D, Kashanchi K, Tajran S, Heilbronn C, Anderson C, Francis DO, Gelbard A, Verma SP (2019) The online support group as a community: a thematic content analysis of an online support group for idiopathic subglottic stenosis. Ann Otol Rhinol Laryngol 128(4):293-299. https://doi.org/10.1177/0003489418820348

5. Langer JC (2013) Hirschsprung disease. Curr Opin Pediatr 25(3):368-374. https://doi.org/10.1097/MOP.0b013e328360c2a0 
6. Wang C, Li L, Cheng W (2015) Anorectal malformation: the etiological factors. Pediatr Surg Int 31(9):795-804. https://doi.org/10. 1007/s00383-015-3685-0

7. Schletker J, Edmonds T, Jacobson R, Ketzer J, Hall J, Trecartin A, Pena A, Bischoff A (2019) Bowel management program in patients with spina bifida. Pediatr Surg Int 35(2):243-245. https:// doi.org/10.1007/s00383-018-4403-5

8. Judd-Glossy L, Ariefdjohan M, Curry S, Ketzer J, Pena A, Bischoff A (2019) A survey of adults with anorectal malformations: perspectives on educational, vocational, and psychosocial experiences. Pediatr Surg Int 35(9):953-961. https://doi.org/10.1007/ s00383-019-04508-y

9. Bischoff A, Levitt MA, Bauer C, Jackson L, Holder M, Pena A (2009) Treatment of fecal incontinence with a comprehensive bowel management program. J Pediatr Surg 44(6):1278-1283. https://doi.org/10.1016/j.jpedsurg.2009.02.047

10. Jacobs R, Boyd L, Brennan K, Sinha CK, Giuliani S (2016) The importance of social media for patients and families affected by congenital anomalies: a Facebook cross-sectional analysis and user survey. J Pediatr Surg 51(11):1766-1771. https://doi.org/10. 1016/j.jpedsurg.2016.07.008

11. Reppucci M, de La Torre L, Peña A, Pickett K, Ketzer J, Bischoff A (2021) The use of social media among the pediatric colorectal community. In: 28th International Meeting of the Pediatric Colorectal Club, Athens, Gree, August 28-30

12. Hill CE, Knox S, Thompson BJ, Williams EN, Hess SA, Ladany $\mathrm{N}$ (2005) Consensual qualitative research: an update. J Couns Psychol 52(2):196

13. Ryan G, Vyrostek S, Aminoff D, Booth K, Driesbach S, Fisher M, Gerberick J, Haanen M, Mullins C, Parker L, Schwarzer N (2020) Importance of education and the role of the patient and family in the care of anorectal malformations. Semin Pediatr Surg 29(6):150990. https://doi.org/10.1016/j.sempedsurg.2020.150990

14. Grano C, Bucci S, Aminoff D, Lucidi F, Violani C (2013) Does mothers' perception of social support mediate the relationship between fecal incontinence and quality of life of the child? Pediatr Surg Int 29(9):919-923. https://doi.org/10.1007/ s00383-013-3358-9

Publisher's Note Springer Nature remains neutral with regard to jurisdictional claims in published maps and institutional affiliations. 